
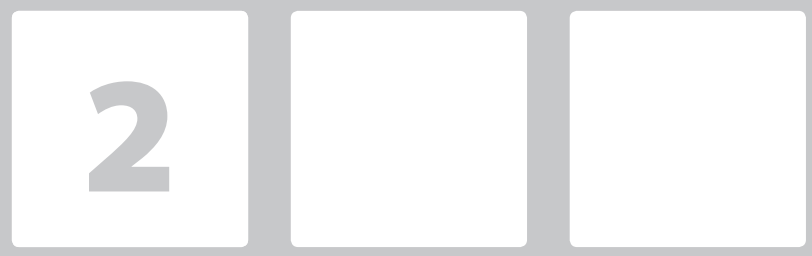

\title{
ESTRATÉGIAS DE HEDGE PARA O ETANOL BRASILEIRO: ANÁLISE A PARTIR DE OPERAÇÕES DE CONTRATOS FUTUROS DOMÉSTICO E ESTRANGEIROS
}

\section{Hedging strategies for Brazilian ethanol: an analysis of domestic and foreign futures contracts operations}

\section{Daniel Henrique Dario Capitani}

Professor Doutor, Universidade Estadual de Campinas, Faculdade de Ciências Aplicadas (FCA/UNICAMP), email:danieldc@unicamp.br

\section{Julyerme Matheus Tonin}

Professor, Universidade Estadual de Maringá (UEM)

email:jmtonin@uem.br

\section{José César Cruz Júnior}

Professor Adjunto, Universidade Federal de São Carlos, Departamento de Economia (Ufscar/Sorocaba) email:cesarcruz@ufscar.br

\section{RESUMO}

As mudanças ocorridas no mercado internacional de biocombustíveis provocaram significativas alterações no mercado de etanol brasileiro. Diante dessa situação, este trabalho objetivou avaliar a eficiência do hedge e risco de base do etanol brasileiro utilizando contratos futuros no Brasil e EUA entre 2010 a 2019. Para isso, foi utilizado um modelo de hedge simultâneo de câmbio e preços. Os resultados indicam que a utilização de contratos estrangeiros não foi eficiente na maior parte dos anos, sobretudo em razão das variações cambiais, choques de oferta e intervenções nos mercados de combustíveis de ambos os países. Além disso, a operação com contratos americanos oferece maior variação no risco de base, sobretudo pelo fator cambial. No entanto, observa-se que, nos períodos de menores volatilidades cambiais e de redução dos efeitos domésticos na regulação do mercado, a efetividade do hedge com contratos estrangeiros foi próxima daquela utilizando contratos nacionais, sugerindo-se uma alternativa na procura por contratos com maior liquidez.

Palavras-chave: Etanol; Contratos Futuros; Eficiência do Hedge; Risco de Base

\section{ABSTRACT}

Several changes in biofuels international market has influenced local market dynamics and price risks. This study proposes to assess the hedging effectiveness and basis risk of the Brazilian ethanol using domestic and U.S. futures contract from 2010 through 2019. We use the simultaneous hedging for prices and exchange rate. Our overall results indicate that hedging strategies with U.S. futures contracts were less efficient and caused higher basis risk than strategies that use domestic contracts. The results were primarily influenced by exchange rate volatility, supply shocks, and biofuels policies implemented in Brazil and U.S. While the use of foreign contracts presents participants with additional basis risk, we found that during periods of less domestic regulation and lower exchange rate variation, hedging strategies that use foreign contracts are nearly as effective as those using domestic futures contracts. Thus, market participants in Brazil should consider using foreign contracts in their hedging strategies, particularly during periods of lower expected exchange risk

Keywords: Ethanol; Futures Contracts; Hedging Effectiveness; Basis Risk. 


\section{INTRODUÇÃO}

$\mathrm{O}$ aumento da participação das economias emergentes no mercado internacional, ao longo das últimas décadas, levou a uma série de debates e estudos voltados ao melhor entendimento da estabilidade financeira destes países e suas políticas de incentivo à produção. Para os mercados agrícolas, cada vez mais integrados e com políticas comerciais menos restritivas, surge a necessidade de melhor compreensão acerca da descoberta de preços e da mitigação de riscos utilizando, dentre outros, os mercados de derivativos (HOHENSEE; LEE, 2006; LIEN; ZHANG, 2008). Considerando esta abordagem, diversos estudos empíricos se propuseram a estudar mercados que passaram por reformas e se aprimoraram comercialmente, mas que ainda apresentam deficiências no uso de ferramentas de gestão de risco.

Com mudanças significativas em seu funcionamento ao longo das últimas décadas, tem-se o setor sucroenergético brasileiro. Inicialmente, na década de 1970, este setor foi impulsionado por políticas federais na regulação da produção e distribuição de etanol e, posteriormente, com a drástica redução nas intervenções, pela adoção de novas tecnologias e aumento na demanda por etanol hidratado. Nesta transição, o setor se consolida como o segundo em geração de valor na agricultura brasileira, ratificando o Brasil como maior produtor mundial de cana-de-açúcar e açúcar, e segundo maior de etanol.

Similarmente às observações de Lien e Zhang (2008) para diferentes mercados emergentes, o setor sucroenergético, mesmo passando por profundas mudanças estruturais - como uma menor intervenção governamental e maior diversificação do capital empregado nos novos empreendimentos - apresenta pouca participação de seus agentes no mercado de futuros. Ambos os contratos futuros que atendem o setor energético na BM\&FBOVESPA (açúcar e etanol) apresentam uma procura por parte de hedgers, o que resulta em baixa liquidez (QUINTINO; DAVID, 2013; THOMSON REUTERS, 2019).

Em relação ao etanol, sobretudo, as incertezas se dão não somente nas oscilações de oferta e demanda nos mercados doméstico e internacional, mas também em relação aos mandatos federais para utilização do etanol anidro, aos preços e estoques do açúcar e à regulação no preço da gasolina no mercado brasileiro (MILANEZ et al., 2012; RODRIGUES; BACCHI, 2016). Destaca-se, portanto, a necessidade de procurar mecanismos que possibilitem reduzir os riscos para os agentes envolvidos em sua produção (FRANKEN; PARCELL, 2003).

Assumindo como premissa o potencial de mitigação do risco de preços ao se tomar uma posição no mercado futuro, esta pesquisa tem como avaliar a eficiência do hedge para o etanol brasileiro. Para isso, são consideradas operações utilizando tanto o contrato futuro doméstico da BM\&FBOVESPA/B3 ${ }^{1}$, quanto os dois principais de referência internacional (NYMEX e CBOT). Complementarmente, levando em conta a análise da efetividade do hedge utilizando os contratos estrangeiros, o hedge de câmbio simultâneo também é considerado.

O primeiro passo da presente pesquisa consiste na análise estatística das bases em todas as operações de hedge propostas. Para isso, calcula-se o risco de base utilizando-se de medidas de dispersão tradicionais, como o desvio-padrão e o coeficiente de variação, além do value-at-risk (V@R). A utilização do V@R possibilita observar separadamente os lados da distribuição das bases e calcular suas magnitudes extremas. Segundo Grootveld e Hallerbach (1999), o uso do V@R é mais consistente e relevante no contexto de gestão de risco em comparação com as medidas de dispersão que analisam ambos os lados da distribuição.

Após o cálculo do risco de base, assume-se uma adaptação ao modelo de hedge simultâneo proposto por Nayak e Turvey (2000). Nesta adaptação, realizam-se simulações para determinação da viabilidade e eficiência do hedge de etanol e câmbio a partir das operações com contratos estrangeiros, e compara-se com a eficiência do hedge direta simulada a partir do contrato doméstico de etanol. O uso deste modelo se justifica pelo fato de trazer inovações aos modelos estáticos tradicionais, os quais não permitiam incorporar às análises o hedge simultâneo com mais de um contrato, tal como apontado por Souza et al. (2012).

\footnotetext{
1 Ressalta-se que, com a fusão da BM\&FBovespa com a Cetip, em 2017, a nomenclatura da nova bolsa passa a ser Brasil, Bolsa Balcão (B3). Como o estudo apresenta dados coletados no repositório antigo (BM\&FBovespa) e atual (B3), para facilitação da compreensão, utiliza-se da nomenclatura anterior, BM\&FBovespa.
} 
De forma geral, esta pesquisa tem como propósito oferecer uma visão mais ampla da utilização de contratos futuros por parte dos agentes atuantes no setor sucroenergético brasileiro, discorrendo sobre a importância do debate acerca dos mercados de derivativos agropecuários. Além disso, com o uso de medidas de risco para avaliar a base, diferentes alternativas de hedge e de hedge cambial podem contribuir para um melhor entendimento e promover maior interesse pela utilização do hedge como forma de mitigação de risco por parte desses agentes e promover maior liquidez para o contrato brasileiro.

\section{FUNDAMENTAÇÃO TEÓRICA}

\subsection{O setor sucroenergético e a liquidez do contrato futuro de etanol no Brasil}

Principal produtor mundial de cana-de-açúcar, o Brasil tem apresentado uma moagem de 600 a 700 milhões de toneladas por ano-safra, desde o início da década de 2010. Especificamente, a produção nacional de etanol na safra 2018/19 foi de 33 bilhões de litros ( 9,9 bilhões de litros de etanol anidro e 23,1 bilhões de litros de etanol hidratado). Tal volume coloca o país como segundo maior produtor mundial, após os EUA ${ }^{2}$. No que tange às exportações, o Brasil figura como maior exportador mundial. Porém, enfatiza-se que o volume comercializado internacionalmente é relativamente baixo em relação à produção total. Isso representa, no caso brasileiro, entre 5 a $8 \%$ do volume total, tomando como base o período 2014/15 a 2018/19 (UNICA, 2019).

Ao analisar o potencial brasileiro de suprir o crescimento recente da demanda mundial por etanol, Silva (2017) simula alguns cenários, considerando o potencial de incremento no consumo dos EUA e União Europeia. Utilizando modelagem de equilíbrio geral computável, a autora revela que, independente do cenário projetado, é estimado o crescimento da produção e exportação brasileira a médio e longo prazo. No entanto, a ressalva que se faz se dá em relação às influências no curto prazo sobre os preços domésticos, com possíveis aumentos na volatilidade dos preços do etanol, o que, por sua vez, poderia impulsionar a demanda por mecanismos que reduzam as incertezas dos agentes.

Já Rodrigues e Bacchi (2016) buscaram compreender os determinantes que impulsionaram a produção doméstica de etanol hidratado a partir do início da década de 2000. Para isso, utilizaram um modelo autorregressivo para o período de 2003 a 2013. Muito embora o paradoxo entre consumo e produção parecesse evidente após a implantação dos carros flex no país, os autores identificaram que o consumo depende também de outros fatores. Entre estes fatores, está a associação entre o aumento da renda e o posterior aumento do crédito e isenção tributária, que impulsionou o mercado automobilístico e possibilitou a renovação da frota de veículos no país, incentivando o consumo de etanol. No entanto, os autores ressaltam que as políticas posteriores de regulação no preço da gasolina e pouco direcionamento de políticas específicas aos biocombustíveis alavancariam as incertezas sobre o mercado de etanol, o que impulsionaria os riscos dos agentes no setor.

Analisando a questão conjuntural e aspectos inerentes às políticas públicas direcionadas ao mercado de biocombustíveis, Milanez et al. (2012) apontam a necessidade de criação de mecanismos de incentivos que permitam acelerar o crescimento da oferta de etanol. Para isso, os autores sugerem três medidas conjuntas. Primeiramente, incentivos à produção de cana-de-açúcar, sobretudo concernente à renovação dos canaviais, utilizando-se de instrumentos de política agrícola ou incentivos creditícios. A segunda medida ressaltada é a ampliação da capacidade industrial. Os autores enfatizam que questões tributárias sobre o etanol tendem a desestimular o aumento da produção. Então, sugerem a desoneração de alguns tributos, como a CIDE e o IPI, e melhor coordenação dos estados na carga do ICMS. Por fim, elencam a necessidade de incentivar a inovação tecnológica no campo e na indústria, abordando o papel estratégico de órgãos como o BNDES e FINEP para cooperação em programas específicos.

Apesar de diferentes estudos apontarem elementos que potencializem as incertezas no setor sucroenergético, observa-se uma ainda baixa utilização dos contratos futuros de etanol na bolsa brasileira. 
Tomando como base os contratos em aberto com vencimentos mensais de etanol hidratado da BM\&FBovespa para o ano de 2019 e comparando com os contratos mensais de etanol em aberto na NYMEX, observa-se que o número de contratos na bolsa brasileira varia entre 1,2\% a 18,5\% em relação ao número de contratos da bolsa americana (com média de 7,1\%). Se analisados os volumes financeiros envolvidos nas transações, a diferença é ainda maior, evidenciando a baixa liquidez do contrato brasileiro (THOMSON REUTERS, 2019).

Quintino e David (2013) apontam que as razões para a baixa liquidez do contrato de etanol na BM\&FBovespa são relacionadas a quatro fatores principais. Primeiramente, chamam atenção à estruturação do setor e sua competitividade, sugerindo que grandes grupos ofertantes de etanol terem uma concentração de mercado relevante, especialmente quando se olham as exportações, permite uma melhor negociação nas vendas, limitando suas reais necessidades de gerir riscos no mercado de derivativos. Outro ponto que colocam é a respeito das intervenções governamentais no preço da gasolina, sobretudo a partir de 2011, que impactou de forma significativa a volatilidade do preço do etanol, estabelecendo artificialmente um patamar para as variações de preços e desestimulando as estratégias de hedge, sobretudo do lado do hedger de compra. Uma possível razão complementar à baixa liquidez do contrato sugerida pelos autores é a concentração da distribuição do etanol, o que limita a livre concorrência e cria barganha de preços por parte dos compradores no mercado doméstico. Por fim, os autores elencam a possibilidade de cross-hedge com outros contratos futuros estrangeiros que possam atrair, principalmente, hedgers interessados no comércio internacional e especuladores.

Referente à questão de integração entre os mercados de etanol do Brasil e EUA, Capitani et al. (2018) investigaram se há existência de um preço internacional de referência para esta commodity, partindo da premissa de que os dois maiores ofertantes do produto detêm uma expressiva parcela de mercado. O estudo em questão utilizou um modelo autorregressivo com correção de erros e testou a causalidade entre os preços de etanol em ambos os mercados, considerando também os preços do açúcar no Brasil, do milho nos EUA, e do petróleo no merca- do internacional. Seus resultados sugerem uma baixa integração entre os preços dos biocombustíveis e suas matérias-primas nos dois países, sendo o petróleo um importante determinante dos preços e atuando como referência para os mercados domésticos de biocombustíveis.

\subsection{Modelos para análise da eficiência do hedge e aplicações para o Brasil}

A mitigação de riscos é uma preocupação constante no setor rural, sendo uma alternativa para a gestão do risco de preços a utilização dos contratos de derivativos agropecuários. Em uma estratégia de hedge, os agentes definem a proporção de suas posições à vista que irão assumir no mercado futuro. Assim minimizam os riscos inerentes às variações nos preços de sua carteira, sendo que esta proporção é conhecida como razão de hedge de mínima variância (FIGLEWSKI, 1984; NETZ, 1996; LORD; TURNER, 1998).

Neste contexto, credita-se a Johnson (1960) e Stein (1961) a abordagem de hedge em termos de um portfólio ótimo de mínima variância. Johnson (1960) deu início à formalização teórica para determinação da proporção ideal da produção no mercado à vista a ser hedgeada no mercado futuro, adaptando a teoria de Markowitz ao problema do hedging. Em linhas gerais, a formulação de Johnson (1960) permite derivar a razão de hedge que minimiza o risco da operação, assumindo que tal risco é dado pela variância das mudanças no valor do portfólio hedgeado, em que a minimização da variância de sua carteira resultará na razão de hedge ótima, tal como:

$$
h_{j}^{*}=\rho_{\Delta S, \Delta F} \frac{\sigma_{s}}{\sigma_{f}}=\frac{\operatorname{cov}\left(\Delta S_{t}, \Delta F_{t}\right)}{\operatorname{Var}\left(\Delta F_{t}\right)}
$$

Sendo $\rho_{\Delta S, \Delta S} ; \sigma_{s}$ e $\sigma_{f}$ os desvios dos preços à vista e futuros, respectivamente; $\operatorname{Cov}\left(\Delta \mathrm{S}_{\mathrm{t}}, \Delta \mathrm{F}_{\mathrm{t}}\right)$ a covariância entre as diferenças dos preços à vista e futuros; $\operatorname{Var}\left(\Delta \mathrm{F}_{\mathrm{t}}\right)$ e $\operatorname{Var}\left(\Delta \mathrm{S}_{\mathrm{t}}\right)$ a variância da diferença dos preços futuros e físicos, respectivamente.

O arcabouço teórico da estratégia de hedge recebeu importantes contribuições ao longo do tempo. Por exemplo, a ideia de full hedge deu lugar à noção 
de que os agentes demandam hedge para apenas uma parcela da carteira (EDERINGTON, 1979). Primeiramente, alguns estudos testaram a possibilidade de utilizar mais de uma posição de contratos futuros na composição da carteira, criando a noção de cross hedging (ANDERSON; DANTHINE, 1981; MANFREDO et al. 2000). Outros analisaram esta questão sob a ótica do hedge em múltiplos períodos (BAESEL; GRANT, 1982). Adicionalmente, outros estudos foram conduzidos para testar as hipóteses de determinação simultânea (HEIFNER, 1972) ou não (PECK, 1975) dos preços físicos e futuros, comparando os resultados às concepções teóricas (KAHL, 1983).

Ademais, cabe destacar os avanços metodológicos na estimação da razão ótima de hedge e grau ótimo de efetividade do hedge. O modelo tradicional de Johnson (1960) é baseado em uma regressão pelo método de mínimos quadrados ordinários (MQO), que considera mudanças nos preços à vista em virtude de variações nos preços futuros, sendo a razão de hedge de mínima variância encontrada pelo intercepto de sua equação (CHEN et al., 2003; CRUZ JÚNIOR, 2009).

Por sua vez, Myers e Thompson (1989) utilizam ferramentas disponíveis na teoria de séries temporais para generalizar o modelo tradicional. Neste contexto, os autores destacaram que o parâmetro de deslocamento da regressão estimada fornece apenas a razão oriunda da covariância incondicional entre as variáveis dependentes e explicativas para a variância incondicional das variáveis explicativas.

Neste ínterim, a modelagem de variância condicional presente no modelo Autoregressive Conditional Heterocedasticity (ARCH) desenvolvido por Engle (1982) e sua generalização (GARCH), proposta por Bollerslev (1986), não era aplicada ao problema de hedge. O estudo empírico de Baillie e Myers (1991), com a proposição de um modelo bivariado de variância condicional, inaugura a abordagem dinâmica da estratégia de hedge. Contudo, Engle e Kroner (1995) propuseram uma especificação multivariada de variância condicional. Neste contexto, estabeleceu-se uma dicotomia na literatura, sendo empreendido esforços para comparar os resultados da abordagem tradicional (estática) com a abordagem dinâmica da operação de hedge.
Entretanto, como o resultado obtido em uma operação de hedge não pode ser dissociado do comportamento da base, o entendimento e previsão do risco de base tornam-se fatores de fundamental importância para o hedger na consecução da sua estratégia de gestão risco. Assim, Viswanath (1993) considera a dependência das convergências possíveis dos preços físicos e futuros e da razão de hedge em relação tanto à duração do hedge, quanto ao tempo de necessário para que o contrato atinja sua maturidade. Para o autor, ao invés de incluir um amplo número de defasagens, conforme proposto por Myers e Thompson (1989), deve-se incluir a base no modelo de regressão.

Em outra vertente teórica, emergia-se a preocupação com o trader offshore, ou seja, agentes que buscavam proteção de preço com contratos futuros de bolsas de outros países, e que, por isso, precisariam gerir o risco cambial presente em sua operação de hedge (THOMPSON; BOND, 1987). Ao analisarem esta questão, Nayak e Turvey (2000) abarcaram o problema de gestão de risco do trader offshore avaliando o caso de produtores de milho de Ontário (Canadá) que utilizavam contratos futuros nas bolsas norte-americanas. Os autores propuseram uma estratégia de gestão de risco para mitigar conjuntamente os riscos cambial, de produção e de preços, proporcionado aos produtores um hedge de renda.

A principal contribuição de Nayak e Turvey (2000) foi a expansão do portfólio de ativos para gestão concomitante de dois ou mais riscos, criando o conceito de hedge simultâneo. Na literatura recente sobre o tema, cabe destacar a contribuição de Mun e Morgan (2003) que avaliaram a exposição dos principais bancos dos EUA aos riscos cambial e de juros, comparando o desempenho das estratégias de hedge separadas ou simultâneas para cobertura destes riscos. No mercado agropecuário, cabe destacar a contribuição de Frank et al. (2011) que estudaram o mercado canadense de carne bovina.

No Brasil, Souza et al. (2012) analisaram o hedge simultâneo para produtores de soja na região de Rondonópolis utilizando contratos futuros da BM\&FBovespa. Os autores aplicaram um modelo de hedge simultâneo do risco de preços e taxa de câmbio para o cálculo da efetividade do hedge. Em diferentes cenários, os autores concluíram que o hedge simul- 
tâneo de soja e câmbio é mais eficiente na redução do risco de perdas na receita dos produtores de soja do que o hedge de preço ou de câmbio realizados separadamente.

Por sua vez, Kairalla (2015), usando o modelo de hedge de variância mínima, simulou diferentes estratégias para o exportador de café brasileiro, como o não uso de hedge, o hedge individual de café ou de câmbio e o hedge simultâneo de café e de câmbio na BM\&FBOVESPA. Enquanto que Tonin et al. (2015) aplicaram a mesma abordagem para a soja e o café, simulando estratégias de hedge com recortes temporais condizentes com os períodos de safra destas culturas e mantendo a posição até o encerramento do contrato futuro, captando o efeito de convergência de base, conforme postulado por Viswanath (1993). Em ambos os estudos, verifica-se a superioridade do hedge simultâneo em relação às demais estratégias parciais, tanto para o café quanto para a soja, em todas as regiões e períodos analisados.

\section{METODOLOGIA}

A modelagem teórica de hedge simultâneo para commodities agropecuárias baseia-se no estudo de Nayak e Turvey (2000), que aplicou o conceito de hedge de renda para os produtores de milho de Ontário no período de 1975 a 1996. Para Lien e Tse (2000), o estudo da eficiência das estratégias de hegde, na abordagem seminal de Johnson (1960) e Ederington, (1979) recebeu as contribuições de Myers e Thompson (1989), Baillie e Myers (1991), Viswanath (1993), entre outros, que trouxeram avanços metodológicos em termos da especificação do modelo. Mas é com a pesquisa de Nayak e Turvey (2000) que o estudo da estratégia de hedge torna-se mais abrangente, incorporando na análise tanto os contratos futuros da commodity, como os contratos futuros de câmbio e um contrato futuro de produtividade (crop yield future contracts).
A estratégia de hedge realizada com a utilização destes três contratos futuros, juntamente com o preço físico do ativo subjacente, à luz do modelo de mínima variância, pode ser expressa como:

$$
\begin{aligned}
H R= & R+h\left(F_{1}-f_{2}\right) e_{r}+g M\left(Q_{1}-q_{2}\right) e_{r} \\
& +c\left(E_{1}-e_{2}\right)
\end{aligned}
$$

Em que, $H R$ é o hedge da receita; $R$ é a receita à vista no fim do período; $h$ e $c$ são as posições nos mercados futuros da commodity e de câmbio, respectivamente; $F_{1}$ e $f_{2}$ são o preço futuro da commodity, no início e no fim do período, respectivamente ${ }^{3} ; E_{1}$ e $e_{2}$ são as posições futuras de taxa de câmbio, nos períodos inicial e final, respectivamente; $e_{r}$ representa a taxa de câmbio à vista no final do período; $g, M, Q_{1}$ e $q_{2}$ referem-se às posições e preços referente ao crop yield future contracts, não avaliado no presente estudo 4 .

Dado que a BM\&FBovespa não dispõe de um substituto próximo para o crop yield future contracts, a abordagem seminal de hedge de renda de Nayak e Turvey (2000) é implementada de forma parcial, sob a ótica de hedge simultâneo de preço e câmbio (HS):

$$
\mathrm{HS}=\mathrm{R}+\mathrm{hfe}_{\mathrm{r}}+\mathrm{ce}
$$

Sendo que, por simplificação, $f=F_{1}-f_{2}$; $\mathrm{e}=\mathrm{E}_{1}-\mathrm{e}_{2}$.

Em termos de variância da receita do agente que realiza uma operação de hedge com contratos futuros da commodity de interesse e contratos futuros de câmbio, a equação pode ser descrita como:

$$
\begin{aligned}
\sigma_{\mathrm{HS}}^{2} & =\sigma_{\mathrm{R}}^{2}+\mathrm{h}^{2} \sigma_{\mathrm{fe}_{\mathrm{r}}}^{2}+\mathrm{c}^{2} \sigma_{\mathrm{e}}^{2}+2 \mathrm{~h} \sigma_{\mathrm{R}, \mathrm{fe}_{\mathrm{r}}} \\
& +2 \mathrm{c} \sigma_{\mathrm{R}, \mathrm{e}}+2 \mathrm{~h} c \sigma_{\mathrm{fe}_{\mathrm{r}}, \mathrm{e}}
\end{aligned}
$$

\footnotetext{
3 Hull (1995), mostra que a relação entre o preço à vista atual (So) de uma unidade de moeda estrangeira (medido em Reais) e o preço do contrato futuro adjacente $\left(F_{0}\right)$, na mesma data, é dada por $F_{0}=S_{0} e^{\left(r-r_{f}\right)(T-t)}$. Esta expressão mostra que o diferencial das taxas de juros livres de risco doméstica $(r)$ e estrangeira $\left(r_{f}\right)$ devem expressar a relação temporal e de risco das transações financeiras entre os dois países até o vencimento do contrato ( $T$ - $\left.t\right)$. Esta relação é conhecida como paridade de taxas de juros, e mostra a condição na qual um investidor é indiferente entre manter seus investimentos em um ativo livre de risco no país doméstico, ou no país emissor da moeda estrangeira. Desta forma, assumindo que as cotações atuais dos contratos futuros de câmbio já precificam de forma eficiente o diferencial de juros entre os dois países, elas não são explicitamente apresentadas no modelo.

4 Informações adicionais podem ser obtidas em Nayak e Turvey (2000, p.125).
} 
Em que as variâncias são dadas por $\sigma_{\mathrm{R}}^{2}=\operatorname{var}(\mathrm{R})$; $\sigma_{f_{r}}^{2}=\operatorname{var}\left(\mathrm{fe}_{\mathrm{r}}\right) ; \sigma_{\mathrm{e}}^{2}=\operatorname{var}(\mathrm{e})$ e as covariâncias por $\sigma_{\mathrm{R}, \mathrm{fer}}=\operatorname{cov}\left(\mathrm{R}, \mathrm{fe} \mathrm{r}_{\mathrm{r}}\right) ; \sigma_{\mathrm{R}, \mathrm{e}}=\operatorname{cov}(\mathrm{R}, \mathrm{e}) ; \sigma_{\mathrm{fe}_{\mathrm{r}, \mathrm{e}}}=\operatorname{cov}\left(\mathrm{fe}_{\mathrm{r}}, \mathrm{e}\right)$.

A estratégia ótima de hedge é obtida por meio da minimização da receita do hedge simultâneo em relação às posições no mercado futuro da commodity $(h)$ e taxa de câmbio $(c)$.

$$
\begin{aligned}
& \frac{\partial \sigma_{\mathrm{HS}}^{2}}{\partial \mathrm{h}}=2 \mathrm{~h} \sigma_{\mathrm{fe}_{\mathrm{r}}}^{2}+2 \sigma_{\mathrm{R}, \mathrm{fe} \mathrm{r}}+2 c \sigma_{\mathrm{fe}_{\mathrm{r}}, \mathrm{e}}=0 \\
& \frac{\partial \sigma_{\mathrm{HS}}^{2}}{\partial \mathrm{h}}=2 \mathrm{c} \sigma_{\mathrm{e}}^{2}+2 \sigma_{\mathrm{R}, \mathrm{e}}+2 \mathrm{~h} \sigma_{\mathrm{fe}_{\mathrm{r}}, \mathrm{e}}=0
\end{aligned}
$$

Resolvendo o sistema de equações simultâneas, obtêm-se:

$$
\begin{aligned}
& h^{*}=\frac{1}{1-\rho_{\mathrm{fe}_{\mathrm{r}}, \mathrm{e}}^{2}}\left(-\frac{\sigma_{\mathrm{R}, \mathrm{fe}_{\mathrm{r}}}}{\sigma_{\mathrm{fe}_{\mathrm{r}}}^{2}}+\frac{\sigma_{\mathrm{R}, \mathrm{e}} \sigma_{\mathrm{fe}_{\mathrm{r}}, \mathrm{e}}}{\sigma_{\mathrm{fe}_{\mathrm{r}}}^{2} \sigma_{\mathrm{e}}^{2}}\right) \\
& \mathrm{c}^{\star}=\frac{1}{1-\rho_{\mathrm{fe}_{\mathrm{r}}, \mathrm{e}}^{2}}\left(-\frac{\sigma_{\mathrm{R}, \mathrm{e}}}{\sigma_{\mathrm{e}}^{2}}+\frac{\sigma_{\mathrm{R}, \mathrm{fe}_{\mathrm{r}}} \sigma_{\mathrm{fe}_{\mathrm{r}}, \mathrm{e}}}{\sigma_{\mathrm{fe}_{\mathrm{r}}}^{2} \sigma_{\mathrm{e}}^{2}}\right)
\end{aligned}
$$

Em que $h^{*}$ e $c^{*}$ são as posições de mínimo risco nos mercados futuros da commodity e de câmbio, respectivamente;

$$
\rho_{\mathrm{fe}_{\mathrm{r}}, \mathrm{e}}^{2}=\left(\frac{\sigma_{\mathrm{fe}_{\mathrm{r}}, \mathrm{e}}}{\sigma_{\mathrm{fe}_{\mathrm{r}}} \sigma_{\mathrm{e}}}\right)^{2}
$$

representa o quadrado do coeficiente de correlação entre os preços futuros expressos em moeda local e os preços futuros de taxa de câmbio.

Em seguida, substitui-se as posições ótimas no mercado futuro da commodity e no mercado futuro da taxa de câmbio na equação 4 , obtendo:

$$
\begin{aligned}
\left(\sigma_{\mathrm{HS}}^{\mathrm{RM}}\right)^{2}= & \sigma_{\mathrm{R}}^{2}+\left(\mathrm{h}^{\star}\right)^{2} \sigma_{\mathrm{fe}_{\mathrm{r}}}^{2}+\left(\mathrm{c}^{\star}\right)^{2} \sigma_{\mathrm{e}}^{2}+ \\
& +2 \mathrm{~h}^{\star} \sigma_{\mathrm{R}, \mathrm{fe}}+2 \mathrm{c}^{\star} \sigma_{\mathrm{R}, \mathrm{e}}+2 \mathrm{~h}^{\star} \mathrm{c} \sigma_{\mathrm{fe}_{\mathrm{r}}, \mathrm{e}}
\end{aligned}
$$

Sendo assim, a redução absoluta do risco é dada pela diferença entre a receita sem hedge e a receita com hedge simultâneo.

$$
\begin{aligned}
\mathrm{RR}_{\mathrm{HS}} & =\sigma_{\mathrm{R}}^{2}-\left(\sigma_{\mathrm{HS}}^{\mathrm{RM}}\right)^{2} \\
& =\frac{1}{\theta \sigma_{\mathrm{e}}^{2}}\left(\frac{\sigma_{\mathrm{R}, \mathrm{fe}_{\mathrm{r}}} \sigma_{\mathrm{fe}_{\mathrm{r}}, \mathrm{e}}}{\sigma_{\mathrm{fe}_{\mathrm{r}}}^{2}}-\sigma_{\mathrm{R}, \mathrm{e}}\right)^{2}+\frac{\sigma_{\mathrm{R}, \mathrm{fe}_{\mathrm{r}}}}{\sigma_{\mathrm{fe}_{\mathrm{r}}}^{2}}
\end{aligned}
$$

Em que $\theta=1-\rho_{f_{\mathrm{e}, \mathrm{e} e}}^{2}$ com as demais variáveis já especificadas anteriormente.

Para avaliar apenas a utilização de hedge de preços futuros, assume-se que $\sigma_{\mathrm{R}, \mathrm{e}}=0$ e $\sigma_{\mathrm{fer}, \mathrm{e}}=0$. Assim:

$$
\mathrm{RR}_{\mathrm{h}}=-\frac{\sigma_{\mathrm{R}, \mathrm{fe}_{\mathrm{r}}}}{\sigma_{\mathrm{fe}_{\mathrm{r}}}^{2}}
$$

Por fim, para avaliar a estratégia com hedge somente com contratos futuros de taxa de câmbio, assume-se que $\sigma_{\mathrm{R}, \mathrm{fer}}=0$ e $\sigma_{\text {fer,e }}=0$. Assim:

$$
\mathrm{RR}_{\mathrm{c}}=-\frac{\sigma_{\mathrm{R}, \mathrm{e}}}{\sigma_{\mathrm{e}}^{2}}
$$

Com isso é possível realizar a análise comparativa entre as estratégias de hedge com contratos futuros da commodity, o hedge com contratos futuros de taxa de câmbio e o hedge simultâneo de ambos.

\subsection{Dados utilizados}

As estratégias de hedge são avaliadas a partir dos preços médios à vista diários de etanol hidratado de Paulínia, estado de São Paulo, disponibilizado pelo CEPEA/ESALQ. Em relação aos contratos futuros de etanol hidratado, os dados foram obtidos na BM\&FBovespa, na New York Mercantile Exchange (NYMEX) e na Chicago Board of Trade (CBOT). Ainda, o hedge de câmbio será analisado utilizando-se o contrato futuro de dólar na BM\&FBovespa. Por fim, a taxa de câmbio doméstica à vista refere-se ao dólar de venda PTAX800, sendo obtida junto ao Banco Central do Brasil (BCB). Os dados utilizados compreendem 
o período de 19/05/2010 a 30/04/2019, perfazendo o total de 2.130 observações.

Como recorte temporal, utilizou-se a janela temporal de um ano, condizente com o período da safra brasileira de cana-de-açúcar, ou seja, o agente inicia a estratégia no início de maio do ano corrente e encerra sua posição em abril do ano subsequente. Deste modo, a análise de hedge simultâneo permite comparar os resultados obtidos entre as safras 2010/11 a 2016/19, perfazendo entre 237 e 242 observações em cada análise, em decorrência dos feriados nos locais de comercialização e bolsas de mercadorias.

Para os contratos futuros de etanol hidratado e de câmbio foram construídas séries de primeiro vencimento em aberto, com o intuito de garantir que o vencimento futuro com maior liquidez sempre fosse utilizado na análise. Entretanto, por simplificação, os custos de rolagem de hedge que ocorreriam na implementação desta estratégia não são contabilizados na análise. Cabe destacar que o encerramento da estratégia de hedge ocorre com o encerramento do contrato futuro, possibilitando captar na análise efeitos de oscilações na base e convergência de preços físicos e futuros no vencimento do contrato.
Enfatiza-se, ainda, que os contratos futuros utilizados na análise têm especificações distintas. $\mathrm{O}$ contrato de etanol platts swap negociado na NYMEX tem liquidação financeira e equivale a 42.000 galões. $\mathrm{O}$ contrato futuro de etanol da CBOT tem entrega física e equivale a 29.000 galões. Por fim, o contrato futuro da B3 com liquidação financeira é especificado em $30 \mathrm{~m}^{3}$. Para fins de comparação os preços foram convertidos em US\$/litro, sendo possível comparar as estratégias de hedge simultâneo, hedge de preço e hedge de câmbio realizados com contratos futuros da CBOT e NYMEX, e compará-los com o hedge de preços realizados na BM\&FBovespa.

\section{RESULTADOS E DISCUSSÃO}

Primeiramente, analisando o comportamento das bases dos três contratos em relação aos preços à vista em São Paulo ${ }^{5}$, nota-se que o fator cambial, como era de se esperar ${ }^{6}$, torna significativamente maior a variação da operação com contratos futuros estrangeiros, com picos de oscilação em maior magnitude que a operação via BM\&FBovespa (Figura 1).

Figura 1 Comportamento das bases analisadas, 2010-2019

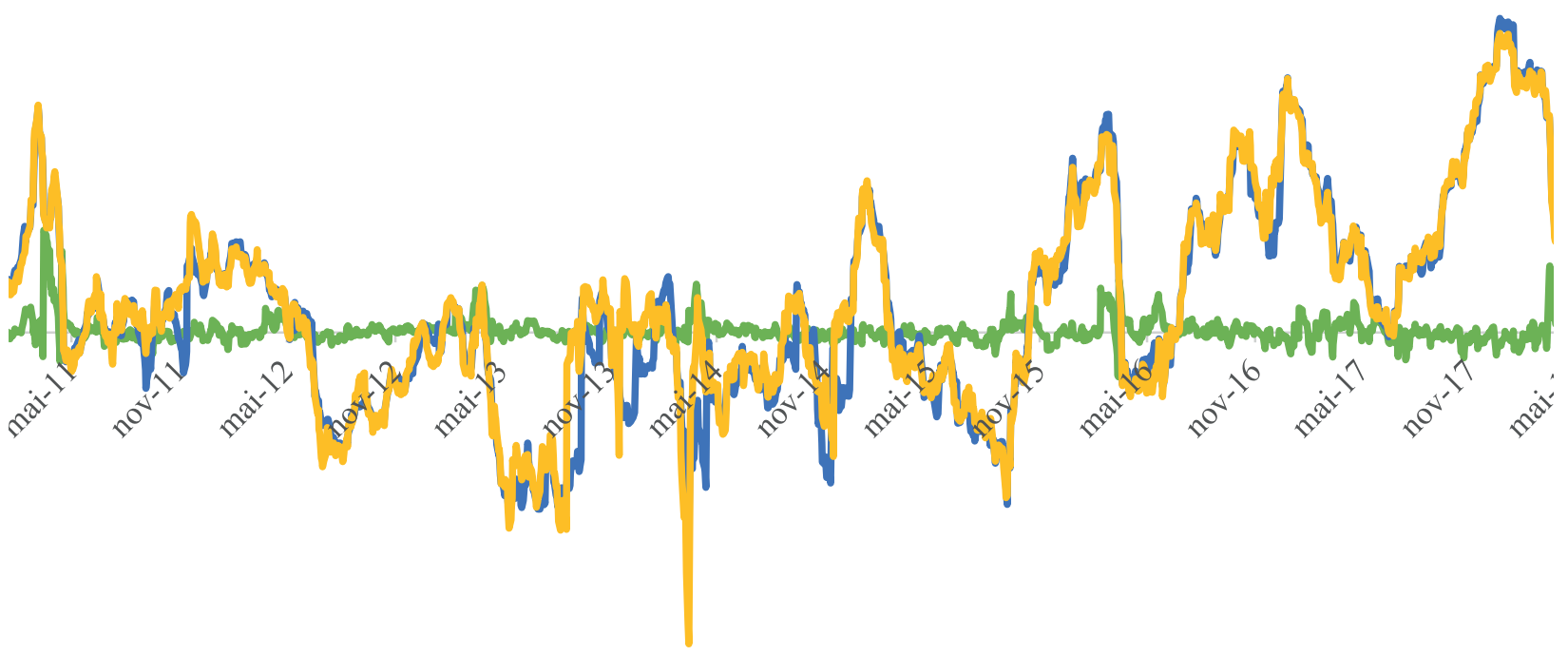

Fonte: Dados da pesquisa.

\footnotetext{
5 Com os preços futuros da CME e NYMEX já convertidos para Reais.

6 Para melhor compreensão do padrão de comportamento da taxa de câmbio no período, ver figura 2, anexa ao artigo.
} 
Operando-se contratos da BM\&FBovespa, nota-se que a base possui média próxima a zero e baixos desvios em relação à média, com os valores mínimos e máximos apresentando baixa amplitude. Já para os casos da operação via CME ou NYMEX, embora a base média também tenda a zero, o intervalo de oscilação entre os valores mínimos e máximos são maiores, conforme apontado na tabela 1 .

Tabela 1 Estatística descritiva e medidas de risco para as bases, 2010-2019

\begin{tabular}{l|c|c|c}
\hline & $\begin{array}{c}\text { BM\&F } \\
\text { BOVESPA }\end{array}$ & NYMEX & CME \\
\hline Média & 0,006 & 0,097 & 0,109 \\
\hline Desvio-Padrão & 0,036 & 0,277 & 0,267 \\
\hline Mínimo & $-0,128$ & $-0,682$ & $-0,828$ \\
\hline Máximo & 0,272 & 0,836 & 0,795 \\
\hline Curtose & 15,791 & $-0,349$ & $-0,177$ \\
\hline Assimetria & 2,980 & 0,314 & 0,236 \\
\hline Mediana & 0,000 & 0,068 & 0,082 \\
\hline LPM & 0,015 & 0,131 & 0,123 \\
\hline UPM & 0,025 & 0,118 & 0,117 \\
\hline VaR ${ }_{95 \% \text { lower }}$ & $-0,026$ & $-0,409$ & $-0,378$ \\
\hline VaR ${ }_{95 \% \text { upper }}$ & 0,061 & 0,335 & 0,346 \\
\hline
\end{tabular}

Ainda em relação às médias das bases, para todos os casos, os valores próximos à nulidade indicam que as operações de futuros de etanol, nos contratos analisados, tendem a favorecer tanto hedgers de venda (ex.: usinas), quanto de compra (ex.: distribuidoras), a depender do momento em que desejam operar. Ou seja, as bases não apresentam um comportamento muito negativo ou positivo que beneficie, majoritariamente, um só lado interessado em operar. Neste sentido, as métricas adicionais para analisar os desvios positivos e negativos das bases zero, bem como as variações extremas das bases em ambas as caudas de suas distribuições de probabilidade, também sugerem que os comportamentos são similares para todos os contratos, com variações de magnitudes próximas nos extremos de ocorrência de bases positivas ou negativas. Contudo, tal como observado anteriormente, na figura 1, os limites das variações das bases dos contratos da CME e NYMEX são significativamente superiores aos da BM\&FBovespa, sendo o valor em risco (V@R) em torno de R\$ $(0,38)$ a $\mathrm{R} \$(0,41)$ adicionais para as bases negativas da operação com os contratos americanos e R $\$ 0,33$ a $R \$ 0,35$ nas bases positivas, ratificando o aumento do risco de base na operação cruzada com contratos estrangeiros.

Fonte: Resultados da Pesquisa

Tabela 2 Matriz de Correlação dos preços físicos e futuros diários de etanol, 2010/11 - 2018/19

\begin{tabular}{l|c|c|c|c|c|c}
\hline & Etanol Físico & $\begin{array}{c}\text { Dólar } \\
\text { Físico }\end{array}$ & $\begin{array}{c}\text { Preço Futuro } \\
\text { CME }\end{array}$ & $\begin{array}{c}\text { Preço Físico } \\
\text { NYMEX }\end{array}$ & $\begin{array}{c}\text { Preço Futuro } \\
\text { BM\&FBov. }\end{array}$ & $\begin{array}{c}\text { Dólar Futuro } \\
\text { BM\&FBov. }\end{array}$ \\
\hline Etanol Físico & 1 & & & & & \\
\hline Dólar Físico & 0,728 & 1 & & & & \\
\hline PF CME & $-0,571$ & $-0,851$ & 1 & & & \\
\hline PF NYMEX & $-0,590$ & $-0,859$ & $-0,142$ & 1 & & \\
\hline PF BM\&F & 0,992 & 0,733 & $-0,581$ & $-0,600$ & & 1 \\
\hline Dólar Futuro & 0,728 & 0,997 & $-0,851$ & $-0,859$ & & 0,732 \\
\hline
\end{tabular}

Fonte: Resultados da Pesquisa

* PF representa os preços futuros.

Em relação às variáveis de preços físicos e futuros em questão, para todo o período em análise, é possível identificar uma elevada correlação entre dólar físico e futuro e entre o preço do etanol no mercado físico com o contrato futuro da BM\&FBOVESPA (Tabela 2). 
A correlação elevada entre dólar físico e futuro deve-se à utilização do primeiro vencimento em aberto do contrato futuro que, devido à sua elevada liquidez e por ter vencimentos listados para todos os meses do ano, reflete rapidamente o comportamento do preço spot do dólar. Por sua vez, a correlação entre preço físico e contrato futuro da BM\&FBOVESPA deve-se ao fato de que a praça de referência utilizada no mercado físico é a mesma utilizada como referência do contrato futuro.

Cabe destacar que além da baixa correlação negativa entre os contratos futuros da NYMEX e CME com o preço doméstico do etanol hidratado brasileiro, esta correlação apresentou mudanças significativas ao longo dos períodos analisados (se analisados separadamente por ano-safra). Por exemplo, a elevada correlação positiva dos contratos futuros da CME e NYMEX com os preços físicos do etanol brasileiro na safra 2010/11 sugere um indicativo de bons resultados para a estratégia de hedge offshore. Porém, rapidamente se converte em uma correlação nula nas três safras seguintes, possivelmente pela intensificação da intervenção na política de combustíveis e choques cambiais, para então apresentar um padrão de correlação negativa (Tabela 3 ).

Tabela 3 Correlação entre os contratos futuros de etanol hidratado da CME e NYMEX com o mercado doméstico de etanol e câmbio do Brasil, 2010/11 - 2018/19

\begin{tabular}{c|c|c|c|c}
\hline \multirow{2}{*}{ Safra } & \multicolumn{2}{|c|}{ Preço Futuro CME } & \multicolumn{2}{c}{ Preço Futuro NYMEX } \\
\cline { 2 - 5 } & Etanol Físico & Dólar Físico & Etanol Físico & Dólar Físico \\
\hline $2010 / 11$ & 0,892 & $-0,915$ & 0,873 & $-0,897$ \\
\hline $2011 / 12$ & $-0,073$ & $-0,727$ & 0,075 & $-0,570$ \\
\hline $2012 / 13$ & $-0,026$ & $-0,076$ & 0,011 & $-0,100$ \\
\hline $2013 / 14$ & 0,006 & $-0,327$ & $-0,092$ & $-0,469$ \\
\hline $2014 / 15$ & $-0,514$ & $-0,771$ & $-0,487$ & $-0,771$ \\
\hline $2015 / 16$ & $-0,632$ & $-0,603$ & $-0,695$ & $-0,626$ \\
\hline $2016 / 17$ & 0,025 & 0,338 & 0,205 & 0,362 \\
\hline $2017 / 18$ & $-0,644$ & $-0,262$ & $-0,694$ & $-0,278$ \\
\hline $2018 / 19$ & $-0,334$ & $-0,383$ & $-0,411$ & $-0,285$ \\
\hline
\end{tabular}

Fonte: Resultados da Pesquisa.

Para Gomes (1987), o risco associado à estratégia de hedge é uma composição do risco da mercadoria e do respectivo contrato futuro. Logo, depende da ordem de grandeza e da direção das variações conjuntas dos preços em ambos os mercados. Assim, a avaliação da correlação entre séries de preços físicos e futuros pode indicar a direção da relação linear entre essas duas variáveis.

Nota-se que, neste período, os biocombustíveis, entre eles o etanol, passam a ser considerados como bens energéticos e não mais como produtos agrícolas, conforme estabelecido pela lei 12490/2011 (BRASIL, 2011). Simultaneamente, se intensifica a política de subvenção ao preço da gasolina. Com a intervenção institucional, criaram-se barreiras ao preço do etanol em decorrência do seu elevado grau de substituição com a gasolina. Isso corroborou com fatores que contribuíram para o grau de descolamento entre os preços dos mercados doméstico e internacional do etanol, evidenciando a abrupta redução da correlação entre estes preços.

Com base na metodologia proposta por Nayak e Turvey (2000), aplicada ao problema de hedge simultâneo, a magnitude da redução do risco é avaliada em termos de variâncias e covariâncias das variáveis. Neste contexto, a elaboração da matriz de variância e covariância, expressa na Tabela 4, fornece todos os elementos necessários para a posterior aplicação da modelagem de hedge simultâneo. 
Tabela 4 Matriz de variância e covariância para os recortes temporais de análise das estratégias de hedge para o etanol, 2018/11 - 2018/19

\begin{tabular}{|c|c|c|c|c|c|c|c|c|c|}
\hline & $2010 / 11$ & $2011 / 12$ & $2012 / 13$ & $2013 / 14$ & $2014 / 15$ & $2015 / 16$ & $2016 / 17$ & $2017 / 18$ & $2018 / 19$ \\
\hline $\operatorname{Var}(\mathrm{R})$ & 0,057 & 0,006 & 0,007 & 0,013 & 0,004 & 0,083 & 0,032 & 0,042 & 0,024 \\
\hline $\operatorname{Var}\left(f e_{r}\right)-C M E$ & 0,022 & 0,017 & 0,008 & 0,044 & 0,056 & 0,006 & 0,004 & 0,005 & 0,004 \\
\hline $\operatorname{Var}\left(f e_{\mathrm{r}}\right)-$ NYMEX & 0,022 & 0,017 & 0,007 & 0,031 & 0,066 & 0,007 & 0,006 & 0,006 & 0,006 \\
\hline $\operatorname{Var}\left(f_{\mathrm{r}}\right)-\mathrm{BMF}$ & 0,051 & 0,007 & 0,004 & 0,012 & 0,004 & 0,077 & 0,035 & 0,045 & 0,013 \\
\hline $\operatorname{Var}(\mathrm{e})$ & 0,004 & 0,012 & 0,001 & 0,011 & 0,100 & 0,113 & 0,019 & 0,007 & 0,031 \\
\hline $\operatorname{Cov}\left(R_{,} \mathrm{fe}_{\mathrm{r}}\right)-\mathrm{CME}$ & 0,032 & $-0,001$ & $-0,000$ & 0,000 & $-0,008$ & $-0,013$ & $-0,000$ & $-0,009$ & $-0,005$ \\
\hline $\operatorname{Cov}\left(R, f e_{r}\right)-N Y M E X$ & 0,031 & 0,001 & 0,000 & $-0,002$ & $-0,008$ & $-0,017$ & 0,003 & $-0,011$ & $-0,004$ \\
\hline $\operatorname{Cov}\left(R, f e_{r}\right)-B M \& F$ & 0,053 & 0,006 & 0,005 & 0,012 & 0,004 & 0,079 & 0,033 & 0,043 & 0,014 \\
\hline $\operatorname{Cov}(R, e)$ & $-0,013$ & 0,004 & $-0,001$ & 0,005 & 0,0100 & 0,069 & $-0,008$ & 0,003 & 0,009 \\
\hline $\operatorname{Cov}\left(f_{r^{\prime}}, e\right)-C M E$ & $-0,009$ & $-0,010$ & $-0,000$ & $-0,007$ & $-0,058$ & $-0,015$ & 0,003 & $-0,002$ & $-0,005$ \\
\hline $\operatorname{Cov}\left(f e_{r^{\prime}} e\right)-$ NYMEX & $-0,009$ & $-0,008$ & 0,000 & $-0,009$ & $-0,062$ & $-0,017$ & 0.004 & $-0,002$ & $-0,003$ \\
\hline
\end{tabular}

Fonte: Resultados da Pesquisa

Utilizando-se de tais informações e aplicando-as à análise do hedge de mínima variância, é possível comparar os resultados entre as diferentes estratégias possíveis a serem adotadas na proposição deste estudo. Observa-se na tabela 5, entre a segunda e a quarta coluna, a redução da variância para o hedger brasileiro, adotando a estratégia de operar futuros ou câmbio isoladamente, ou de partir para uma estratégia simultânea entre câmbio e futuros de etanol da CME ou NYMEX. A princípio, a redução da variância é significativa nas três estratégias apenas na safra 2010/11, decaindo nas estratégias com hedge cambial ou hedge simultâneo nos anos subsequentes, e tornando-se nula no hedge direto com contratos estrangeiros. Posteriormente, nota-se uma ligeira recuperação nos anos de 2015/16 e 2017/18, em todas as estratégias, ocorrendo variações para baixo nos anos de 2016/17 e 2018/19, principalmente nas operações que não envolvem o hedge simultâneo (Tabela 5).

Tais resultados podem ser melhor avaliados ao se observar a perda na eficiência do hedge das operações simultâneas, tal como expressos nas três colunas finais da tabela 5, em detrimento da operação do hedge direto a partir do contrato de etanol hidratado na BM\&FBovespa (Tabela 6). Observa-se que, no comparativo entre os períodos analisados, há uma queda abrupta da eficiência do hedge na estratégia com os contratos estrangeiros, indicando que no período entre 2011/12 e 2014/15, aumentou-se a diferença da efetividade da operação simultânea em comparação com o hedge direto na BM\&FBovespa. Ou seja, mesmo se os agentes adotassem estratégias de hedge simultâneo, observariam um declínio da eficiência dessa estratégia neste período.

Tabela 6 Resultados da estratégia de hedge de preço com base nos contatos futuros de etanol hidratado nas bolsas CME, NYMEX e BM\&FBOVESPA, 2010/11 - 2018/19

\begin{tabular}{c|c|c|c}
\hline Safra & CME & NYMEX & BM\&F \\
\hline $2010 / 11$ & $80,28 \%$ & $78,71 \%$ & $95,06 \%$ \\
\hline $2011 / 12$ & $42,27 \%$ & $43,25 \%$ & $90,52 \%$ \\
\hline $2012 / 13$ & $22,77 \%$ & $22,52 \%$ & $89,41 \%$ \\
\hline $2013 / 14$ & $20,35 \%$ & $19,46 \%$ & $96,08 \%$ \\
\hline $2014 / 15$ & $28,05 \%$ & $26,31 \%$ & $96,26 \%$ \\
\hline $2015 / 16$ & $57,47 \%$ & $61,44 \%$ & $98,06 \%$ \\
\hline $2016 / 17$ & $13,68 \%$ & $23,80 \%$ & $97,69 \%$ \\
\hline $2017 / 18$ & $41,34 \%$ & $48,06 \%$ & $97,27 \%$ \\
\hline $2018 / 19$ & $22,26 \%$ & $16,86 \%$ & $81,96 \%$ \\
\hline
\end{tabular}

Fonte: Resultados da Pesquisa.

Nota: Dado que o contrato futuro de etanol hidratado da BM\&FBOVESPA é cotado em $\mathrm{R} \$ / \mathrm{m} 3$, para efeito de comparação, as cotações das demais bolsas foram convertidas na mesma unidade de medida. 
Tabela 5 Resultados em termos de redução das variâncias em relação ao cenário-base, para todas as estratégias de hedge para o etanol, 2010/11 - 2018/19

\begin{tabular}{|c|c|c|c|c|c|c|c|c|}
\hline & & \multirow{2}{*}{$\begin{array}{l}\text { Cenário- } \\
\text {-base } \\
\text { Sem hedge }\end{array}$} & \multicolumn{3}{|c|}{ Redução da variância } & \multicolumn{3}{|c|}{$\%$ Total } \\
\hline & & & $\begin{array}{c}\text { Hedge de } \\
\text { preço }\end{array}$ & $\begin{array}{l}\text { Hedge } \\
\text { cambial }\end{array}$ & $\begin{array}{c}\text { Hedge } \\
\text { simultâneo }\end{array}$ & $\begin{array}{c}\text { Hedge de } \\
\text { preço }\end{array}$ & $\begin{array}{l}\text { Hedge } \\
\text { cambial }\end{array}$ & $\begin{array}{c}\text { Hedge } \\
\text { simultâneo }\end{array}$ \\
\hline \multirow{9}{*}{$\sum_{U}^{\omega}$} & $2010 / 11$ & 0,057 & 0,045 & 0,042 & 0,046 & $79,21 \%$ & $73,10 \%$ & $80,28 \%$ \\
\hline & $2011 / 12$ & 0,006 & 0,000 & 0,001 & 0,003 & $0,53 \%$ & $24,46 \%$ & $42,27 \%$ \\
\hline & $2012 / 13$ & 0,007 & 0,000 & 0,001 & 0,002 & $0,07 \%$ & $22,36 \%$ & $22,77 \%$ \\
\hline & 2013/14 & 0,013 & 0,000 & 0,002 & 0,003 & $0,01 \%$ & $17,91 \%$ & $20,35 \%$ \\
\hline & $2014 / 15$ & 0,004 & 0,001 & 0,001 & 0,001 & $26,35 \%$ & $22,85 \%$ & $28,05 \%$ \\
\hline & 2015/16 & 0,083 & 0,033 & 0,042 & 0,047 & $39,71 \%$ & $51,19 \%$ & $57,47 \%$ \\
\hline & $2016 / 17$ & 0,032 & 0,000 & 0,004 & 0,004 & $0,06 \%$ & $11,49 \%$ & $13,68 \%$ \\
\hline & $2017 / 18$ & 0,042 & 0,017 & 0,001 & 0,017 & $41,34 \%$ & $2,86 \%$ & $41,34 \%$ \\
\hline & 2018/19 & 0,023 & 0,005 & 0,003 & 0,005 & $21,05 \%$ & $11,93 \%$ & $22,26 \%$ \\
\hline \multirow{9}{*}{$\sum_{z}^{\stackrel{x}{u}}$} & 2010/11 & 0,057 & 0,043 & 0,042 & 0,045 & $75,84 \%$ & $73,10 \%$ & $78,71 \%$ \\
\hline & $2011 / 12$ & 0,006 & 0,000 & 0,001 & 0,003 & $0,56 \%$ & $24,46 \%$ & $43,25 \%$ \\
\hline & $2012 / 13$ & 0,007 & 0,000 & 0,001 & 0,002 & $0,01 \%$ & $22,36 \%$ & $22,52 \%$ \\
\hline & 2013/14 & 0,013 & 0,000 & 0,002 & 0,002 & $0,84 \%$ & $17,91 \%$ & $19,46 \%$ \\
\hline & $2014 / 15$ & 0,004 & 0,001 & 0,001 & 0,001 & $23,65 \%$ & $22,85 \%$ & $26,31 \%$ \\
\hline & $2015 / 16$ & 0,083 & 0,040 & 0,042 & 0,051 & $48,17 \%$ & $51,19 \%$ & $61,44 \%$ \\
\hline & $2016 / 17$ & 0,032 & 0,001 & 0,004 & 0,008 & $4,19 \%$ & $11,49 \%$ & $23,80 \%$ \\
\hline & $2017 / 18$ & 0,042 & 0,020 & 0,001 & 0,020 & $47,97 \%$ & $2,86 \%$ & $48,06 \%$ \\
\hline & $2018 / 19$ & 0,019 & 0,003 & 0,000 & 0,003 & $16,83 \%$ & $1,08 \%$ & $16,86 \%$ \\
\hline
\end{tabular}

Fonte: Resultados da Pesquisa

Com base no resultado apresentado na Tabela 6, o declínio da efetividade dos contratos offshore para gestão do risco de preço do etanol brasileiro e a manutenção em níveis inferiores a 30\% de redução da variância até a safra 2014/15 indicam um descasamento entre o mercado doméstico e o mercado internacional. Isso se dá, tal como sugerido anteriormente, por razões dos determinantes de oferta e demanda internos de etanol nos EUA e Brasil, principais produtores e consumidores mundiais do produto. Por exemplo, o aumento substancial da oferta americana em seu mercado doméstico nos anos recentes (SILVA, 2017) e a manutenção da política de intervenção do governo brasileiro nos preços da gasolina (MILANEZ et al., 2012; RODRIGUES; BACCHI, 2017), reduzindo a possibilidade de variação dos preços de etanol em seu mercado local.
Neste sentido, estes fatores podem ter sido substanciais para que os preços de cada mercado fossem formados a partir dos determinantes de sua oferta e demanda doméstica, levando os preços futuros a não representarem adequadamente os preços no mercado internacional, ainda mais se considerar que a produção de ambos os países corresponde majoritariamente à oferta internacional de etanol (CAPITANI et al., 2018). Um indicativo mais evidente dessas flutuações pode ser a aproximação da eficiência das duas estratégias a partir de 2015/16, período em que o mercado de combustíveis no Brasil sofre menor interferência e que a oferta americana passa a crescer em menor escala em virtude do cumprimento dos mandatos federais para o etanol anidro. 


\section{CONSIDERAÇÕES FINAIS}

Este trabalho se propôs a investigar a eficiência e razão ótima do hedge em operações cruzadas envolvendo o etanol brasileiro com os contratos futuros de maior liquidez internacionalmente, como os da NYMEX e CME, e comparando-os com a efetividade da operação com contratos na BM\&FBOVESPA. Além disso, o artigo visou calcular o risco de base destas operações.

Em relação ao risco de base, nota-se que as operações de todos os contratos futuros apresentam bases com médias próximas a zero para o período como um todo, indicando menores desvios aos hedgers operando em ambos os lados de compra e venda. No entanto, observam-se oscilações significativas em determinados momentos, as quais são potencializadas nas operações de hedge com os contratos da CME e NYMEX, sobretudo em razão do fator cambial. Tais constatações sugerem que o risco de base pode apresentar valores de maior magnitude na operação com contrato estrangeiro, com valor em risco superior às operações domésticas.

Contudo, a efetividade do hedge mostrou-se significativamente menor nas operações com contratos futuros estrangeiros, se comparado com o uso do contrato da BM\&FBOVESPA, o qual apresentou alta eficiência em todos os períodos. No período considerado na análise, observa-se que somente na safra 2010/11, as eficiências dos três contratos ficam mais próximas a equivalerem-se, isto é, a operação do hedge com contratos americanos mostrou-se similarmente eficiente à operação com contrato doméstico, mostrando-se uma alternativa pontual para operacionalização do hedger brasileiro em busca de contratos de etanol com maior liquidez. No entanto, deve-se levar em consideração que, na maior parte do período, entre 2012/13 e 2014/15, e em 2017/18, tal eficiência revela-se reduzida, mostrando-se o contrato doméstico a alternativa mais viável para operação do etanol. Em outros períodos, como 2011/12, 2015/16 e 2018/19, a eficiência da estratégia de hedge simultâneo se aproxima do hedge direto com contrato doméstico, porém, ainda em patamares aquém do observado no início da década.

Algumas razões podem ser elencadas como determinantes desta variação abrupta na eficiência do hedge com contratos estrangeiros. O primeiro período da amostra conciliava-se com o avanço do consumo de etanol no mercado norte-americano, dado a obrigatoriedade de cumprimento dos mandatos internos de utilização do anidro na gasolina, concomitante à insuficiente produção local, o que fazia recorrer a volumes de importação norte americana, simultaneamente aos aumentos no volume exportado pelo Brasil. Ou seja, havia maior interconexão de ambos os países no mercado internacional, o que possivelmente poderia explicar uma maior convergência de seus preços futuros, incorrendo, assim, em maior eficiência da operação de hedge cruzado.

Dentre os fatores que podem ter corroborado com essa hipótese, tem-se, do lado americano, (i) a proximidade de sua autossuficiência na produção do etanol, consolidando-se como o maior produtor mundial; (ii) a forte seca durante o ano de 2013, afetando severamente sua oferta de milho e, consequentemente, os custos de produção do etanol; e do lado do Brasil, (iii) a intensificação da política de subvenção à gasolina a partir de 2011, com a regulação dos preços nas distribuidoras e postos, reduzindo a possibilidade de movimentação do preço do etanol; (iv) as sucessivas quedas na produtividade da cana-de-açúcar, entre 2011 a 2014, devido a intempéries climáticas no Centro-Sul, mudança no processo de plantio e colheita nas áreas de expansão, além da baixa renovação dos canaviais em decorrência da situação financeira das usinas, o que incorreu em aumento nos custos de produção e queda na produtividade agrícola e industrial; (v) a alta variação na taxa de câmbio Real/Dólar, com a gradual desvalorização da moeda brasileira frente à americana, culminando nos picos históricos das cotações ao longo de 2015, 2016 e 2018, o que pode ter levado o modelo a subestimar a efetividade do hedge em operação simultâneo com contrato cambial.

Estes fatores podem ter sido substanciais para que os preços de cada mercado fossem formados a partir dos determinantes de sua oferta e demanda doméstica, levando os preços futuros a não representarem adequadamente os preços no mercado internacional, ainda mais se considerar que ambos os países são, em grande parte, o próprio mercado internacional desta commodity. Neste sentido, pretende-se, em pesquisa futura, avaliar se tais fatores internos 
nos dois principais produtores mundiais de etanol influenciaram os preços domésticos e internacionais de etanol e se explicam, de alguma forma, a baixa liquidez do contrato brasileiro, uma vez que hedgers exportadores e tradings não enxergam o contrato da BM\&FBOVESPA como um bom sinalizador de preços no mercado externo.

Em relação à análise específica da efetividade do hedge, pretende-se, posteriormente, com maior conjunto de dados e estabilização e maior liberalização dos mercados ofertantes de etanol, realizar análise complementar que agregue uma série de tempo maior e que possibilite corroborar ou refutar as considerações realizadas no presente estudo. Complementarmente, com a possibilidade de utilização de mais observações de dados de etanol em outras praças produtoras brasileiras, cuja série de tempo é mais recente e periodicidade menor (mensal), tem-se o intuito de expandir a análise da eficiência do hedge para diferentes localidades. Ainda, com maior base de dados, será possível avaliar se as simulações de estratégias são mais eficientes usando-se diferentes vencimentos nos contratos futuros em questão. Além disso, entende-se como válida a análise suplementar para melhor compreensão dos elementos que justifiquem a razão da baixa liquidez do contrato futuro de etanol da bolsa brasileira.

Por fim, trabalhos futuros podem também utilizar formas alternativas para determinar os parâmetros do modelo teórico utilizado. As variâncias e covariâncias dos retornos podem, por exemplo, ser estimadas a partir de modelos GARCH multivariados, que também permitam uma análise variante no tempo dos resultados.

\section{REFERÊNCIAS BIBLIOGRÁFICAS}

ANDERSON, R. W.; DANTHINE, J. P. Cross hedging. Journal of Political Economy, Chicago, v. 89, p. 1182-1196, 1981.

BAESEL, J.; GRANT, D. Optimal sequential futures trading. Journal of Finance and Quantitative Analysis, Cambridge, v. 17, n. 1, p. 683-692, 1982.
BAILLIE, R. T.; MYERS, R. J. Bivariate GARCH estimation of the optimal commodity futures hedge. Journal of Applied Economics, Buenos Ayres, v. 6, n. 2, p. 109-124, 1991.

BANCO CENTRAL DO BRASIL - BCB. Séries temporais: taxa de câmbio, dólar comercial. Brasília, 2019. Disponível em: < http://www.bcb.gov.br > Acesso em: 20 mai. 2019.

BOLLERSLEV, T. Generalized autoregressive conditional heteroskedasticity. Journal of Econometrics, Princeton, v. 31, n. 3, p. 307-327, 1986.

CAPITANI, D. H. D.; CRUZ JUNIOR, J. C.; TONIN, J. M. Integration and hedging efficiency between Brazilian and U.S. ethanol markets. Contextus Revista Contemporânea de Economia e Gestão, Fortaleza, v. 16, n. 1, p. 93-117, 2018.

CHEN, S., LEE, C.; SHRESTHA, K. Futures hedge ratios: a review. The Quarterly Review of Economics and Finance, Urbana-Champaign, v. 43, n. 1, 433465, 2003.

CRUZ JÚNIOR, J. C. Modelo de razão de hedge ótima e percepção subjetiva de risco nos mercados futuros. 2009. 100 p. Tese (Doutorado em Economia Aplicada) - Escola Superior de Agricultura "Luiz de Queiroz”, Universidade de São Paulo, Piracicaba, 2009.

EDERINGTON, L. H. The hedging performance of the new futures markets. The Journal of Finance, Pittsburgh, v. 34, n. 1, p. 157-170, mar. 1979.

ENGLE, R. Autorregressive conditional heteroscedasticity with estimates of the variance of United Kingdom inflation. Econometrica, New York, v. 50, n. 4, p. 987-1008, jul. 1982.

ENGLE, R. F.; KRONER, K. F. Multivariate simultaneous generalized ARCH. Econometric Theory, Cambridge, v. 11, n. 01, p. 122-150, 1995.

FIGLEWSKI, S. Hedging performance and basis risk in stock index futures. The Journal of Finance, San Francisco, v. 39, n. 3, p. 657-669, jul. 1984. 
FRANK, J.; BREWEN, D.; PATIÑO, M. J. Marketing strategies in the Canadian beef sector. In: Conference on Applied Commodity Price Analysis, Forecasting and Market Risk Management, 2011, St. Louis. Anais... St. Louis: NCCC-134, 2011, 15 p.

FRANKEN, J. R. V.; PARCELL, J. L. Cash ethanol cross-hedging opportunities. Journal of Agricultural and Applied Economics, Cambridge, v. 35, n. 3, 509-516, 2003.

GOMES, F. C. Determinação da razão de hedge: um estudo sobre as teorias de hedging. Revista de Administração de Empresas. v. 27, n. 4, p. 38-44, 1987.

GROOTVELD, H.; HALLERBACH, W. Variance vs downside risk: is there really that much difference? European Journal of Operational Research, London, v. 114, n. 1, 304-319, 1999.

HEIFNER, R. G. Optimal hedging levels and hedging effectiveness in cattle feeding. Agricultural Economics Research, Washington, D.C., v. 24, n. 1, p. 25-36, abr. 1972.

HOHENSEE, M.; LEE, K. A survey on hedging markets in Asia: a description of Asian derivatives markets from a practical perspective, BIS Papers, Basel, n. 30, p. 261-281, 2006.

HULL, J. Introdução aos mercados futuros e de opções. 2. ed. São Paulo: Bolsa de Mercadorias \& Futuros / Cultura Editores Associados/ Prentice Hall, 1995.

JOHNSON, L.L. The theory of hedging and speculation in commodity futures. The Review of Economics Studies, Oxford, v. 27, n. 1, p. 139-151, jun. 1960.

KAHL, K. H. Effects of economic recovery tax act of 1981 on futures market volume. Journal of Futures Markets, New York, v. 5, n. 2, p. 239-246, 1985.
KAIRALLA, J. C. Avaliação do risco e o impacto do hedge simultâneo de preços e câmbio para o exportador de café no Brasil. 2015. 100 p. Dissertação (Mestrado em Economia Aplicada) - Escola Superior de Agricultura "Luiz de Queiroz", Universidade de São Paulo, Piracicaba, 2015.

LIEN, D.; TSE, Y. K. Some recent developments in futures hedging. Journal of Economic Surveys, New York, v. 16, n. 1, 357-396, 2002.

LIEN, D.; ZHANG, M. A survey of emerging derivatives markets. Emerging Markets Finance and Trade, London, v. 44, n. 2, 39-69, 2008.

LORD, Y. S.; TURNER, S. C. Basis risk for rice. In: American Agricultural Economics Association Annual Meeting, 1998, Milwaukee. Anais... Salt Lake City: AAEA, 1998, 14 p.

MANFREDO, M. R. P.; GARCIA, P.; LEUTHOLD, R. $M$. Time varying multiproduct hedge ratio estimation in the soybean complex: a simplified approach. In: Conference on Applied Commodity Price Analysis, Forecasting and Market Risk Management, 2000, Chicago. Anais... Chicago: NCR-134, 2000, 14 p.

MILANEZ, A. Y.; NYKO, D.; GARCIA, J. L. F.; REIS, B. L. S. F. S. O déficit de produção do etanol do Brasil entre 2012 e 2015: determinantes, consequências e sugestões de política. BNDES Setorial, Rio de Janeiro, n. 35, p. 277-302, mar. 2012.

MUN, K. C.; MORGAN, G. E. Bank foreign exchange rate and interest rate risk management: simultaneous versus separate hedging strategies. Journal of Financial Intermediation, New York, v. 12, n. 3, p. 277-297, 2003.

MYERS, R. J.; THOMPSON, S. R. Generalized optimal hedge ratio estimation. American Journal of Agricultural Economics, New York, v. 71, n. 4, p. 858-868, nov. 1989. 
NAYAK, G. N.; TURVEY, C. G. The simultaneous hedging of price risk, crop yield risk. Canadian Journal of Agricultural Economics, Victoria, v. 48, n. 2, p. 123-140, 2000.

NETZ, J. S. An empirical test of the effect of basis risk on cash markets positions. Journal of Futures Markets, New York, v. 16, n. 3, p. 289-311, mai. 1996.

PECK, A. E. Hedging and income stability: concepts, implications, and an example. American Journal of Agricultural Economics, New York, v. 57, n. 3, p. 410-419, 1975.

QUINTINO, D. D.; DAVID, S. A. Quantitative analysis of feasibility of hydrous ethanol futures contracts in Brazil. Energy Economics, Brighton, v. 40, p. $927-$ 935, 2013.

RENEWABLE FUELS ASSOCIATION - RFA. 2019 ethanol industry outlook: powered with renewed energy. St. Louis, 2019, 31 p. Disponível em: < https://ethanolrfa.org/wp-content/uploads/2019/02/ RFA2019Outlook.pdf >. Acesso em 22 mai. 2019.

RODRIGUES, L.; BACCHI, M. R. P. Light fuel demand and public policies in Brazil, 2002-2013. Applied Economics, St. Louis, v. 48, p. 5300-5313, 2016.

RODRIGUES, L.; BACCHI, M. R. P. Analyzing light fuel demand elasticities in Brazil using cointegration techiniques. Energy Economics, Brighton, v. 65, p. 322-331, 2017.

SILVA, M. R. Mandatos de biocombustíveis e crescimento da demanda mundial de etanol: efeitos sobre a economia brasileira. 2017. 86 p. Dissertação (Mestrado em Economia Aplicada) - Universidade Federal de Juiz de Fora, Juiz de Fora, 2017.
SILVEIRA, R. L. F. da. Análise das operações de cross hedge do bezerro e do hedge do boi gordo no mercado futuro da BM\&F. 2003. 106 p. Dissertação (Mestrado em Economia Aplicada) - Escola Superior de Agricultura "Luiz de Queiroz", Universidade de São Paulo, Piracicaba, 2003.

SOUZA, W. A. R; MARTINES-FILHO, J. G.; MARQUES, P. V. Análise de estratégias de hedge simultâneo para a produção de soja no Centro-Oeste. Revista de Economia, Curitiba, v. 38, n. 2, p. 73-92, mai./ago., 2012.

STEIN, J. L. The simultaneous determination of spot and futures prices. The American Economic Review, Pittsburgh, p. 1012-1025, 1961.

THOMPSON, S. R.; BOND, G. E. Offshore commodity hedging under floating exchange rates. American Journal of Agricultural Economics, New York, v. 69, n. 1, p. 46-55, 1987.

THOMSON REUTERS. Eikon web access: ethanol futures markets. 2019. Disponível em: < https:// www.eikon.thomsonreuters.com $>$. Acesso em: 20 mai. 2019.

TONIN, J. M.; URSO, F. S. P.; MARTINES-FILHO, J. G.; KAIRALLA, J. C. Exposição ao risco brasileiro cambial e estratégia de hedge simultâneo de preços e taxa de câmbio nos contratos futuros de soja e café. In: 5 a Conferência De Gestão de Risco e Comercialização de Commodities, 2015, São Paulo. Anais... São Paulo: BM\&FBovespa, 2015, 17 p.

VISWANATH, P. V. Efficient use of information, convergence adjustments, and regression estimates of hedge ratios. Journal of Futures Markets, New York, v. 13, n. 1, p. 43-53, 1993. 


\section{ANEXOS}

Figura 2 Taxa de câmbio comercial (venda), US\$/R\$, média mensal, maio 2010 a abril 2019

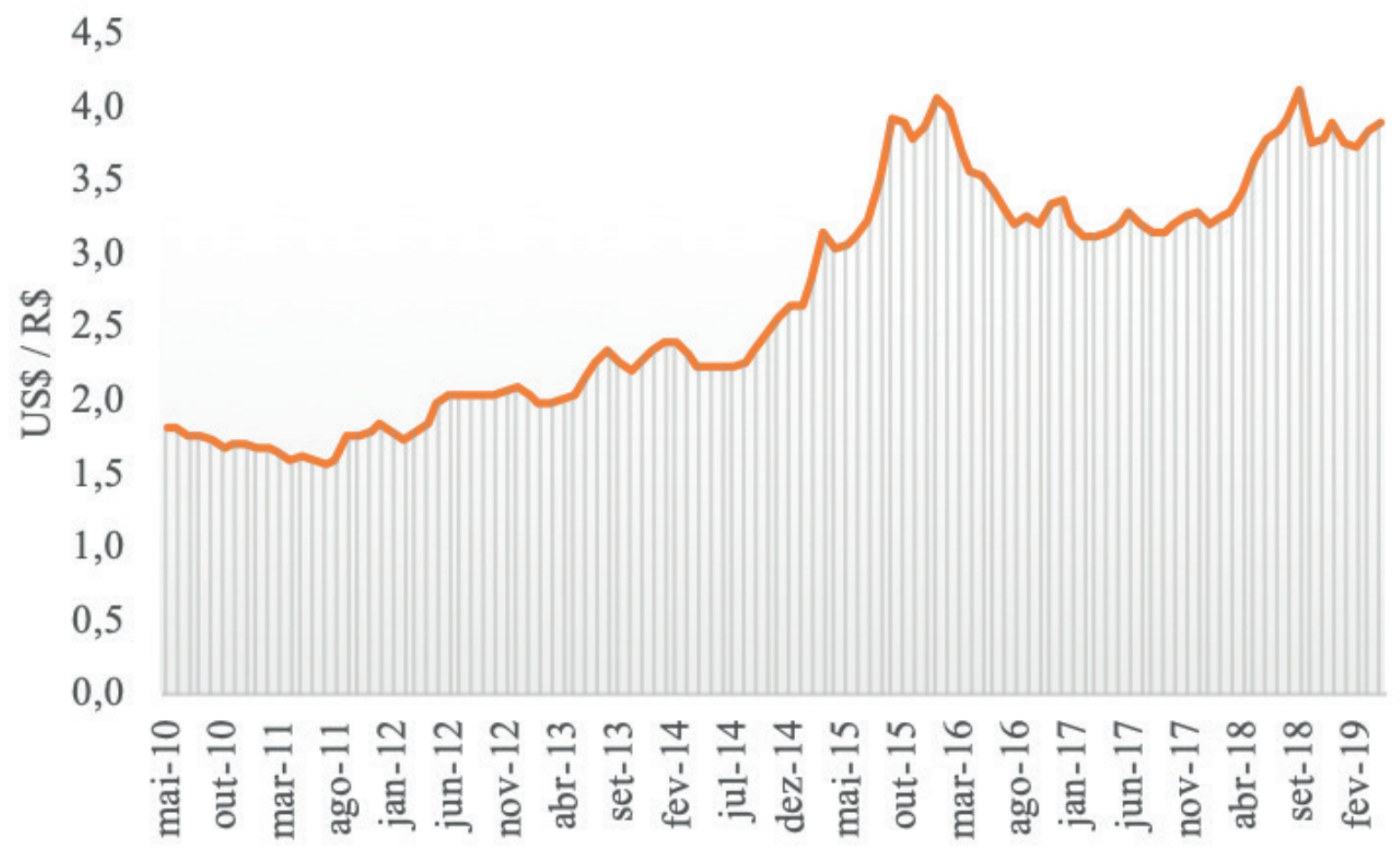

Fonte: BCB (2019) 